\title{
Correction to: Characterization of cork and cork agglomerates under compressive loads by means of energy absorption diagrams
}

Published online: 28 April 2021

○) Springer-Verlag GmbH Germany, part of Springer Nature 2021

\section{Correction to: European Journal of Wood and Wood Products \\ https://doi.org/10.1007/s00107-020-01625-7}

In the original publication of the article, fourth author name was incorrectly published as "Juan Antonio Gomez". The correct name should read as "Jose Antonio Gomez". This has been corrected here. 